\title{
APOSENTADORIA E ESPACOS URBANOS: EXISTE UM LUGAR PARA O
} APOSENTADO?

\author{
JUBILACIÓN Y ESPACIOS URBANOS: ¿HAY UN LUGAR PARA EL JUBILADO? \\ RETIREMENT AND URBAN SPACES: IS THERE A PLACE FOR THE RETIRED?
}

http://dx.doi.org/10.1590/1807-03102015v27n2p428

\author{
Aline Bogoni Costa e Dulce Helena Penna Soares \\ Universidade Federal de Santa Catarina, Florianópolis/SC, Brasil
}

\begin{abstract}
RESUMO
Este estudo objetivou investigar as relações estabelecidas por aposentados com os espaços urbanos centrais da cidade de Florianópolis, tendo por base a leitura de Henri Lefèbvre. Para tanto, realizaram-se incursões a tais espaços com observação de campo, elaboração de registros fotográficos e entrevistas abertas com sete pessoas aposentadas. Adotou-se o método lefebvriano na análise das informações, em três momentos: descritivo, analítico-regressivo e histórico-genético. Os achados da pesquisa permitiram desvelar que as relações dos pesquisados com os espaços urbanos centrais de Florianópolis estão atreladas ao cotidiano, imersas no real e no imaginário, sendo vivenciadas, muitas vezes, por meio de contradições entre a cidade como valor de uso e como valor de troca. Mesmo quando não encontram um "lugar" na cidade, estes aposentados procuram formas de participar e de se inserir como atores nas mudanças em curso dos espaços urbanos que habitam.
\end{abstract}

Palavras-chave: aposentadoria; psicologia; espaços urbanos.

\section{RESUMEN}

Este estudio tuvo como objetivo investigar las relaciones establecidas por jubilados con los espacios urbanos centrales de la ciudad de Florianópolis, en base a la lectura de Henri Lefèbvre. Para tanto, hubo incursiones a dichos espacios con observación de campo, registros fotográficos y entrevistas abiertas con siete personas jubiladas. Adoptamos el método lefebvriano en el análisis de las informaciones, en tres fases: descriptivo, analítico-regresivos e histórico-genéticos. Los resultados de la investigación permitieron descubrir que las relaciones de los encuestados con las áreas urbanas centrales de Florianópolis están vinculadas al cotidiano, inmersas en lo real y lo imaginario, siendo vivenciadas, muchas veces, a través de contradicciones entre la ciudad como valor de uso y como valor de intercambio. Incluso cuando no encuentran un "lugar" en la ciudad, estos jubilados están buscando maneras de participar y de inserirse como actores de los cambios que están ocurriendo en los espacios urbanos en que habitan.

Palabras clave: jubilación; psicología; espacios urbanos.

\begin{abstract}
This study aimed to investigate the relationship of retired people with urban spaces located in the downtown areas of Florianópolis (SC), based on the theories of Henri Lefèbvre. Incursions to these places were performed with field observation, photographic registries and open interviews with seven retired people. The lefebvrian method of analysis was adopted in three different moments: descriptive, analytical-regressive and historical-genetic. Research findings revealed that the relation of the interviewees with downtown urban spaces of Florianópolis are linked to daily routine, lived as reality and imagination, and many times experiencing the city contradictions, as use-value and exchange-value. Even when they can not find a "place" in the city, they look for ways to participate and insert themselves as actors of the changes being made.
\end{abstract}

Keywords: retirement; psychology; urban spaces. 


\section{O "mundo da aposentadoria" nos espaços urbanos}

A procura por um lugar e a estranheza para reconhecer-se; o espaço amplo e o beco ínfimo de sentidos; a lógica posta e aquilo que se esconde; as continuidades e as descontinuidades; o evidente; as expectativas; o que é bonito, o cintilante; estar obrigado e estar desarmado. O poema Rua, de Carlos Drummond de Andrade (1992), inspira uma primeira reflexão sobre a temática deste texto, por descrever, em suas entrelinhas, as relações dos sujeitos com os espaços urbanos na contemporaneidade:

Por que ruas tão largas?

Por que ruas tão retas?

Meu passo torto foi regulado pelos becos tortos de onde venho.

Não sei andar na vastidão simétrica implacável.

Cidade grande é isso?

Cidades são passagens sinuosas

de esconde-esconde

em que as casas aparecem-desaparecem

quando bem entendem

e todo mundo acha normal.

Aqui tudo é exposto

evidente

cintilante.

Aqui obrigam-me a nascer de novo, desarmado.

O olhar do poeta na observação da rua poderia ser o de um trabalhador ou de um aposentado, pois o espaço urbano percebido por Drummond contempla os dois momentos de vida, embora a partir de diferentes vieses: o do "mundo do trabalho" e o do "mundo da aposentadoria".

A expressão "mundo da aposentadoria" pode causar certa estranheza, afinal, esse lugar demanda ser demarcado socialmente? A preocupação das Ciências Humanas, especialmente da Psicologia e da Sociologia, com o "mundo do trabalho" é conhecida e seus estudos favorecem reflexões sobre as relações dos sujeitos com o trabalho na contemporaneidade (Antunes, 1995, 2005; Zanelli, Silva, \& Soares, 2010). O "mundo da aposentadoria", no entanto, ainda carece de uma maior aproximação científica e, especificamente na Psicologia, de estudos e discussões acerca das mudanças de vida vinculadas ao processo de aposentadoria (França \& Vaughan, 2008; Soares \& Costa, 2011; Zanelli et al., 2010), buscando, também, maior entendimento de como ocorre a construção de relações dos aposentados com o espaço e o tempo.
Quanto à espacialidade, o próprio significado de aposentadoria permite algumas reflexões, visto que, em algumas culturas, aposentar-se quer dizer recolherse aos aposentos e, de certa forma, denota o "fechar das portas" para a vida social. Neste sentido, o espaço da aposentadoria torna-se limitado e pouco reconhecido, construindo-se em locais privados. Zanelli et al. (2010) e Soares e Costa (2011) afirmam não haver um espaço socialmente reconhecido para quem se aposenta e, ao se vivenciar a ausência de lugar, muitas pessoas perdem referências importantes em termos identitários.

A temporalidade do "mundo da aposentadoria", por sua vez, revela-se por continuidades e descontinuidades. Segundo Costa (2009), na aposentadoria são comuns os sentimentos de vazio e o desconsolo, mediados pelo afastamento daquilo que estava no centro da vida: o trabalho. Neste processo, haverá continuidades nas relações que permanecerão (família e amigos, por exemplo), no sentimento de construção de uma história de vida (aquilo que foi realizado e o percurso de uma carreira) e nos projetos a realizar, incluindo-se aqueles abandonados no passado para se cumprir as exigências do trabalho. Haverá, também, descontinuidades, vinculadas à insegurança sobre qual caminho seguir, à inexistência de uma agenda fixa ou uma rotina determinada, ao sentirse envelhecendo, às relações que se romperam ou se modificaram quando do afastamento do trabalho. Percebe-se que as descontinuidades sobressaem-se quando a temporalidade é rompida unilateralmente, como nos casos de desvinculação compulsória com o trabalho, seja pela idade obrigatória de aposentadoria, seja pela dificuldade de recolocação no mercado de trabalho ou, ainda, pela invalidez permanente. Contudo, tanto as continuidades como as descontinuidades necessitam ser (res)significadas pela pessoa aposentada, enquanto uma maneira de (re) construir sua identidade no novo momento de vida.

O que dizer desta visão do "mundo da aposentadoria" em relação aos espaços urbanos? Ao se pensar a respeito da aposentadoria nos espaços urbanos, constroem-se diversos questionamentos, dentre eles: se a cidade e os espaços urbanos movemse em função do trabalhar e do capital, qual o lugar do aposentado? Ele insere-se como ator na construção dos espaços urbanos ou passa a estar como expectador apenas? Quais os sentidos que os sujeitos encontram quando aposentados para o mesmo espaço urbano que habitavam quando o trabalho lhes era central? Há direito à cidade e ao habitar ${ }^{1}$ ?

$\mathrm{O}$ direito à cidade não pode ser concebido como um simples direito de visita ou de retorno às cidades tradicionais. Só pode ser formulado como direito à 
vida urbana, transformada, renovada. Pouco importa que o tecido urbano encerre em si o campo e aquilo que sobrevive da vida camponesa conquanto que "o urbano", lugar de encontro, prioridade do valor de uso, inscrição no espaço de um tempo promovido à posição de supremo bem entre os bens, encontre sua base morfológica, sua realização prático-sensível. (Lefèbvre, 1991, p. 108)

$\mathrm{O}$ direito à cidade é central para esta discussão. A cidade referida por Lefèbvre não é apenas linguagem, mas sim uma prática e, enquanto prática, somente é possível compreendê-la embrenhando-se pela experiência urbana com o olhar, o ouvir e o sentir. Voltar todos os sentidos para a cidade possibilita entendê-la como obra, não somente no que é material e estrutural (ruas, casas, pontes, edifícios), mas também no que é representado e imaginado pelas pessoas que a constroem diariamente. E os aposentados, quais possibilidades de construção encontram nos espaços urbanos?

$\mathrm{Na}$ contemporaneidade, as relações de trabalho dinamizam determinantemente os movimentos do espaço urbano ${ }^{2}$. Pode-se dizer que a cidade é o palco onde são apresentados aos sujeitos os meios de produção e de consumo. Constitui-se, assim, como o local de produção capitalista, como o meio ambiente por onde ocorrem as modificações da produção e como cenário onde aparece a mais-valia, a mercantilização e o fetichismo, especialmente no trabalho excedente (Lefèbvre, 2008). Já no urbano há a condição geral de realização do processo de reprodução do capital e, concomitantemente, do produto deste processo que comporta contradições emergentes do conflito entre as necessidades da reprodução do capital e as necessidades da sociedade como um todo (Carlos, 1994).

Enquanto construção humana, a cidade é a expressão concreta dos tempos e dos modos de vida, um produto histórico-social que se apresenta como trabalho materializado e acumulado ao longo das gerações. É, ao mesmo tempo, obra e produto. Obra: quando a cidade projeta-se para o tempo futuro, que se constrói nas tramas do presente, colocando os sujeitos diante da impossibilidade de pensá-la de forma separada da sociedade e do momento histórico em que se vive. Produto: pela cidade conter e revelar ações passadas em seu processo histórico cumulativo (Carlos, 1994).

Verifica-se que, anteriormente ao capitalismo, a cidade era mais obra do que produto, pois, nem a terra nem a cidade haviam se transformado em mercadoria. Antes da industrialização, a cidade era o centro da vida social, da cultura e da política, era lugar de produção de conhecimento e obras. Depois a industrialização tornou-se centro de acumulação de riquezas. Ou seja, antes era mais valor de uso, depois é mais valor de troca. De certa forma, a contradição da mercadoria das fábricas alastrou-se para os espaços urbanos e relações sociais (Lefèbvre, 1991).

Neste contexto, os processos de produção e reprodução da forma urbana não são estáticos, mas dotados de movimento alterando formas, funções, representações e sentidos. Destarte, o espaço urbano passa a ser entendido como um produto social e assume uma realidade própria de acordo com o modo de produção e a sociedade presente, consistindo em mediador para a ação e para o pensamento, funcionando como um meio de produção, de controle e de dominação (Lefèbvre, 2008).

As mudanças ocorrem de forma abrupta na contemporaneidade, orientadas, em especial, pelo avanço tecnológico e pelas novas formas de trabalho. Porém, os maiores interessados na cidade, as pessoas que nela habitam, nem sempre são atores diretos de tais mudanças, visto a omissão e passividade percebidas na dinâmica da construção diária. Ao mesmo tempo, os planejadores urbanos, raramente, levam em consideração os símbolos e sentidos, os desejos e anseios dos que habitam o espaço urbano (Lefèbvre, 2008).

No caso do aposentado, a perda de lugar e a reorganização de seu espaço e tempo confundem-se com os movimentos que percebe da cidade, uma vez que as relações de produção se integram à realidade urbana e, de certa forma, quem se aposenta não está mais inserido como ator no contexto. Tal processo não ocorre sem conflitos e sem algumas dicotomias. Por um lado, a cidade continua a "andar" em um ritmo forte, sendo transformada pela necessidade de produção e (re)construindo espaços que suportam e fomentam a mercadoria, a mais-valia e o fetichismo. Por outro lado, a realidade urbana do aposentado gera segregações, pois o seu ritmo de vida é outro e parece estar na contramão do fluxo que move a cidade e os espaços urbanos.

Cabe ainda considerar que, ao mesmo tempo em que as cidades se transformam, se recriam e se reinventam em curtos períodos de tempo, também ocorrem mudanças demográficas significativas, a exemplo do aumento da expectativa de vida mundial, questão estreitamente relacionada à temática da aposentadoria e cidades. Até 2050, estimam-se grandes mudanças nas pirâmides etárias populacionais, que, durante séculos, estiveram compostas predominantemente de jovens e adultos e passarão, em cerca de quatro décadas, a destacar 
pessoas idosas. Conforme relatório da ONU de 2012, no ano de 2050, as pessoas com 60 anos ou mais serão cerca de 2 bilhões de habitantes, o que representará $20 \%$ da população mundial. A tendência é de que os idosos se tornem cada vez mais numerosos em relação às pessoas mais jovens. Em 2000, a população idosa do planeta superou, pela primeira vez, o número de crianças com menos de 5 anos; em 2050, o número de pessoas com mais de 60 anos ultrapassará a população de jovens com menos de 15 anos (BBC, 2012).

O envelhecimento da população será mais perceptível em países emergentes. Atualmente, cerca de $66 \%$ da população acima de 60 anos vive nos países em desenvolvimento. Em 2050, tal proporção subirá para quase $80 \%$. No Brasil, a previsão é que o número de idosos triplique de 2012 até 2050, passando de 21 milhões para 64 milhões. A partir destas projeções, percebe-se que a proporção de pessoas mais velhas no total da população brasileira passaria de $10 \%$, em 2012, para 29\%, em 2050. Ainda, o número de centenários, pessoas que atingem um século de vida e que tanto instigam profissionais da área da saúde em estudos sobre longevidade, tem crescido em grande escala nos últimos anos (BBC, 2012).

Diante do exposto, no intuito de entender um pouco mais do "mundo da aposentadoria nas cidades", construiu-se o interesse por estudar as relações estabelecidas por aposentados com os espaços urbanos centrais de Florianópolis, a partir da leitura de Henri Lefèbvre. A escolha da cidade de Florianópolis para local da pesquisa deveu-se, sobretudo, ao reconhecimento nacional pelo número de aposentados que atrai, sendo tratada como a "capital do descanso" e como a "Flórida brasileira". Uma reportagem da Revista Veja do ano de 2003 informou que, em 10 anos, o número de pessoas aposentadas vindas de outras cidades para residir em Florianópolis aumentou $55 \%$, sendo que, para cada 100 habitantes, 12 eram aposentados (Souza, 2003). Em 2012, o número de aposentados em Florianópolis representava 17\% da população (IBGE, 2013). Além disso, a cidade de Florianópolis é caracterizada pelo expressivo crescimento demográfico em curto espaço de tempo. Sua população, em 1970, era de 115.547 habitantes, e em 2010, o último censo registrou 421.240, representando um aumento de $365 \%$. A cidade de São Paulo, uma das maiores metrópoles mundiais, que atrai migrantes de todo o país, cresceu $87 \%$ em igual período (IBGE, 2013). Com tal crescimento, Florianópolis passa a requerer maior atenção quanto aos fatores vinculados à urbanidade e, referente aos aposentados, compreender as relações estabelecidas com os espaços urbanos.

\section{Nos caminhos da cidade, um método para entender a vivência da aposentadoria}

A cidade e os espaços urbanos têm sido objeto de estudo de diversas áreas do conhecimento, sendo múltiplos os discursos e os modos de entendê-los. Quando o pesquisador consegue emprestar sua atenção ao urbano, as descobertas se tornam surpreendentes. Com o intuito de experimentar algumas dessas surpresas e tendo em vista o direcionamento teórico do presente estudo, realizou-se a pesquisa através do método qualitativo. Conforme Minayo (2007), esta modalidade de pesquisa responde a questões muito particulares, por se preocupar com um nível de realidade que não pode ser quantificado, contemplando um universo de significados, motivos, aspirações, crenças, valores e atitudes, o que corresponde a um espaço mais profundo das relações, dos processos e dos fenômenos.

Esta pesquisa foi realizada na região central da cidade de Florianópolis, compreendendo espaços muito conhecidos pela população local e amplamente visitados por turistas. Para Lefèbvre (1991), não pode haver cidade sem centralidades, sem um centro dinâmico repleto de urbanidade, de encontros entre o passado e o futuro e de espaços públicos construídos e destruídos a todo tempo.

A centralidade constitui o essencial do fenômeno urbano, mas uma centralidade considerada junto com o movimento dialético que a constitui e a destrói, que a cria e a extingue. $\mathrm{O}$ fato de qualquer ponto ser tomado como centro, é o que caracteriza o espaçotempo urbano. A centralidade não é indiferente àquilo que reúne, ao contrário, necessita de um conteúdo. Amontoados de objetos e produtos nos depósitos, montanhas de frutas nos mercados, multidões, abundância de objetos múltiplos, justaposições, acúmulos, é aqui que se compõe o urbano. (Lefèbvre, 1991, p. 121)

Os locais tomados por centro da cidade de Florianópolis foram:

- a Praça XV de Novembro, conhecida como a Praça da Figueira, fundada em 1662, por Francisco Dias Velho. Foi a partir deste ponto central que a cidade começou a expandir-se, com suas pequenas ruelas, até hoje conservadas em seu estilo viário original. A referida área abriga prédios importantes daquele período, como o Palácio do Governo (Museu Cruz e Souza), a Casa de Câmara e Cadeia, a Catedral Metropolitana e diversas outras construções históricas. Há, nesta praça, uma famosa figueira centenária e, por este motivo, o local costuma ser frequentado por turistas. 
- O calçadão da Rua Felipe Schmidt compõe um cenário com prédios históricos, de arquitetura açoriana, boa parte são construções centenárias restauradas. Por ali circulam, nos dias de semana, milhares de pessoas, destacando-se pelo comércio diversificado e a presença de vendedores ambulantes. Nesta Rua, um ponto de encontro bastante conhecido é o Senadinho, espaço em frente ao Café Ponto Chic (fundado em 1948), com pouco mais de 60 anos de história e que foi palco de muitos acontecimentos históricos da cidade, como a Novembrada ${ }^{3}$, manifestação popular conhecida em todo o país, realizada objetivando romper com o regime militar. Outro aspecto para se observar é um desenho no chão, feito na calçada, representando um plenário com sete cadeiras, a mesa do presidente e a inscrição SPQF - Senado Para Qualquer Fofoca, referenciando este ponto como um local para discussões políticas e para jogar conversa fora. Em tal local, reúnem-se frequentadores assíduos que conversam sobre todos os assuntos, jogam dominó e carteado e contam histórias do passado. Quando se fala de aposentados na cidade de Florianópolis, é provável que o local seja lembrado como uma referência.

- A Alfândega. A primeira alfândega da cidade foi incendiada em 1866 e, para substituí-la, foi construído um prédio de estilo neoclássico, em 1876. No piso térreo funcionam uma galeria de artes, uma feira de artesanato e um bar. À sua frente fica o Largo da Alfândega, local de manifestações populares e shows. Ali se encontram bancas de louças de barro e artesanato e um posto de informações turísticas.

- O Mercado Público de Florianópolis, que é um ponto de referência da cidade, com a característica da valorização da cultura local e do comércio de venda de peixe fresco, lojas de artesanato, bares e restaurantes típicos.

\section{Os interlocutores}

Os participantes do presente estudo foram sete aposentados, sendo cinco homens e duas mulheres, convidados a participar da pesquisa pela pesquisadora, durante três incursões ao centro da cidade de Florianópolis. Por não ter havido um contato prévio com os sujeitos, a pesquisadora esclareceu os objetivos da pesquisa, deixando livre o aceite em participar da mesma ou não. Os nomes utilizados nas citações são fictícios, pseudônimos escolhidos pelos autores.

\section{A busca por informações}

Os procedimentos para a coleta de informações advêm dos fundamentos epistemológicos que a embasam, valendo-se do método lefebvriano ${ }^{4}$. A coleta de informações se deu mediante incursões no centro de Florianópolis (locais mencionados no item " 1 ", contexto da pesquisa), com duração de cerca de quatro horas diárias, em três dias diferentes. Realizaramse: (a) a observação de campo; (b) a elaboração de registros fotográficos; e (c) as entrevistas abertas, onde se verificava se a pessoa era aposentada, discorria-se uma breve apresentação da pesquisa e efetuava-se a pergunta: você pode falar sobre a sua relação com Florianópolis na aposentadoria?, que desencadeava as próximas falas.

A escolha pela entrevista aberta favoreceu um contato maior com o objeto de estudo. De acordo com Minayo (1993), ela pode ser utilizada quando o pesquisador deseja obter o maior número possível de informações acerca de determinado tema, segundo a visão do entrevistado, e também para obter um maior detalhamento do assunto em questão. Favorece a descrição de casos individuais, a compreensão de especificidades culturais para determinados grupos e a comparabilidade de diversos casos.

\section{A análise das informações}

A matriz dialética não pode constituir-se numa doutrina, mas sim dar conta do movimento entre totalidade e especificidade. Isto significa dizer que os achados de uma pesquisa não surgem a priori, mas são construídos historicamente no próprio decorrer do estudo (Frigotto, 1989).

A análise das informações ocorreu por meio de diversas leituras dos registros das observações no diário de campo e das falas dos interlocutores, bem como da análise de textos a respeito dos locais em que aconteceram as incursões e análise das fotografias. A interpretação das informações foi realizada a partir do método lefebvriano, levando-se em conta o tempo histórico, o espaço e a vida cotidiana.

\section{Achados sobre o "mundo da aposentadoria" no centro de Florianópolis}

Antes de falar sobre os achados propriamente ditos, considera-se relevante tecer referência acerca da escolha dos locais e do "encontro" com os participantes na pesquisa de campo, enquanto experiência e sentimentos de pesquisa.

Por mais familiar que seja o local da pesquisa, o novo se revela ao entrar no campo, pois o que move é a inquietação, a possibilidade da descoberta e do encontro com algo que estava aparente. "Ao longo da travessia, o viajante não somente encontra-se, mas 
reencontra-se, já que se descobre o mesmo e o diferente, o idêntico e o transfigurado" (Makowiecky, 2012, p. 81). Durante as incursões desta pesquisa, percebiam-se novos movimentos em meio aos velhos lugares, porque a forma de olhar mudava a cada nova descoberta. $\mathrm{Na}$ Praça XV, por exemplo, as mesas de jogos passaram a fazer parte da paisagem e, antes da pesquisa, não foram sequer percebidas pela pesquisadora. Nesta experiência, o olhar de estrangeiro fez a viagem a um lugar conhecido ser desconhecido, para, após, ser reconhecido novamente.

O "encontro" com os participantes pode ser entendido como o desfecho de identificações entre ambos, visto que, se o olhar do pesquisador fixa em determinado sujeito, é porque há algo que contempla os conhecimentos teóricos e o imaginário. Nesta pesquisa, as representações sociais sobre a aposentadoria foram importantes para o encontro com os possíveis sujeitos. Quem poderia ser aposentado em meio à multidão? Alguém que estivesse sem pressa, andando mais livremente, que aparentasse certa idade por meio das características físicas, etc. No texto que segue, será possível rememorar tal "encontro" que traz consigo muitos significados.

\section{O centro de Florianópolis e os lugares cristalizados}

O centro de Florianópolis traz elementos que se apresentam como atratores para os sujeitos, aproximando-os de ter um lugar no espaço urbano. Conforme Canevacci (1993), atrator é um elemento que mobiliza e prende a atenção, que captura o olhar e os sentidos. Os espaços para o dominó e carteado podem ser entendidos como atratores.

Sou aposentado há quatro anos e não dá pra ficar em casa, a gente fica doente. Por isso, venho pra cá quase todas as tardes... E não tem lugar melhor aqui na cidade, porque estou entre amigos. Um monte de aposentados sem nada pra fazer (risos). Até porque Florianópolis não tem coisas para quem é aposentado, a não ser que se pague muito para isso... Estou esperando minha vez para entrar no jogo. (João, no Senadinho)

A fala de João traz elementos relevantes. Um deles são os jogos, presentes nos locais onde se deu esta pesquisa e que podem ser entendidos como uma forma de estabelecer vínculo com o espaço urbano. Os espaços para jogar são uma característica mobilizadora dos espaços visitados e não têm somente o significado do jogo, mas também da boa conversa na reunião com amigos, seja falando descontraidamente ou discutindo sobre política (que é muito comum nos em tais locais).
Em outras referências, contraditoriamente, alguns dos interlocutores relatam não se sentir participantes da cidade, justificando esse sentimento pela dificuldade de encontrar atividades e entretenimentos acessíveis e gratuitos em Florianópolis. Então, "esperar a vez de jogar", como falou João, tem sentido de "esperar a vez de participar da construção da cidade" enquanto aposentado, afastado da lógica produção-consumo (ou estando somente com o papel de consumidor). De certo modo, a perda de lugar e reorganização dos espaços para o aposentado é dificultada pelos movimentos que percebe da cidade, para os quais nem sempre está inserido e consegue identificar-se.

O que se vê dependerá do lugar de onde e para onde se olha. E, se a posição mudasse? Se o olhar do pesquisador fosse direcionado aos que passam por João? Como um trabalhador apressado percebe João? Constrói-se um novo cenário. Talvez esse trabalhador suponha que João aprecie a cidade, aproveitando o que há de melhor nela, com tempo livre para escolher o que deseje fazer. Neste ir e vir, novas possibilidades acontecem, sendo a cidade construída e desconstruída a todo tempo pelos que nela habitam. Assim, o espaço urbano envolve as contradições da realidade à medida que é social, sendo valor de uso para alguns e valor de troca para outros, ou, ainda, ambos ao mesmo tempo.

Por fim, a atenção da pesquisadora também foi capturada ao verificar os lugares ocupados pelos aposentados. Tais lugares estão marcados e fixados nos espaços urbanos, como é o caso das mesas de jogos e banquetas cimentadas ao chão. Os lugares ocupados pelos aposentados no cenário urbano do centro de Florianópolis parecem estar cristalizados. Por quê? Seriam somente estes os "lugares" possíveis?

\section{O centro de Florianópolis como lugar de encontros e desencontros}

As incursões ao centro de Florianópolis possibilitaram identificar relações de encontros e desencontros dos aposentados consigo mesmos e com suas histórias na cidade. Um dos locais que mais chamou a atenção foi o Senadinho, também conhecido como Café do Ponto Chic. É um espaço que se estabeleceu no centro da cidade, como ponto de encontro para reuniões informais, sendo palco de acontecimentos históricos, especialmente durante o regime militar. Muitas pessoas que o frequentam ainda seguem uma tradição familiar, visto que seus pais também o fizeram. Entretanto, os novos hábitos e relacionamentos contemporâneos se configuram com maior afastamento entre as pessoas, como descreveu Salim Miguel (Carneiro, 1987): "E até o ar bonachão do 'Senadinho', nome 
pelo qual é conhecido o café 'Ponto Chic', a 'boca do inferno' da cidade, na Rua Felipe Schmidt, foi cedendo lugar a faces preocupadas e abatidas".

Peço sempre pra fazer o almoço bem cedo, perto das 11 e 30. Depois de almoçar, venho reservar um lugar aqui para o dominó e cartas. Aposentado não pode ficar em casa, se não a gente briga com a mulher e não tem nada para ver na TV... Hoje em dia todo mundo tem compromisso, então a gente precisa ter também. Este lugarzinho eu gosto, faz parte da minha pessoa. Quando meu pai era vivo, vinha pra cá debater política com os amigos e jogar conversa fora. Só que muita coisa tá ficando diferente aqui. Cada vez diminui mais os amigos, quem se aposenta hoje quer ficar na internet... que já não era coisa do meu tempo. Há 10 anos atrás a gente ficava rodeado aqui e, hoje, isso acontece de vez em quando só. As pessoas passam apressadas aqui e nem percebem que estamos no meio de um lugar que tem história e tradição... Sinto que minha relação com o centro de Florianópolis pode se romper quando percebo que a importância daqui tá diminuindo, porque se não tiver os amigos, acaba meu interesse de vir aqui. (Manoel, no Senadinho)

Florianópolis tem passado por mudanças expressivas, tanto em termos populacionais (citados anteriormente), como nos espaços urbanos. Os aposentados pesquisados expuseram certa dificuldade de se perceber como atores nestas transformações e nos novos lugares constituídos. Isto aparece na fala de Manoel ao descrever o Senadinho como um espaço que faz parte de sua vida e de sua família, todavia questiona a continuidade deste lugar de referência, tendo em vista a diminuição das pessoas que o frequentam e, ao mesmo tempo, a escolha por viver um cotidiano apressado na cidade.

No recorte seguinte, a fala de Ana permite reflexões sobre a inserção no urbano, sem lugares demarcados e sem cristalizações. Ela entende que os espaços deveriam ser de encontro das pessoas antes e depois de se aposentarem.

Florianópolis é uma cidade maravilhosa, porém tem muita coisa para melhorar ainda, porque só a beleza natural não pode ser a diferença. É preciso ter paz nesta cidade, eu percebo que está dificil de encontrar paz aqui, pela muvuca que tá ficando... A cidade precisa ser melhor pensada, senão até as belezas naturais vão se esgotar se não for cuidada.... Florianópolis é engraçada. É grande, mas as pessoas se conhecem, porque não é tão grande assim. É diferente. Então, tem que fazer coisas diferentes para continuar atraindo as pessoas aqui. Sei que muitas pessoas aqui estão dispostas a ter estes lugares de diversão, descontração, energização... encontros! Mas parece que falta algo, porque são poucas as possibilidades e não se tem comunicação, não se promove o encontro das pessoas. Sabe, não acho que o aposentado tenha que ter um lugar só dele em Florianópolis. A gente continua sendo da ilha depois de se aposentar, certo? Então, eu acho que a gente deve ter espaços no tumulto de quem ainda trabalha... que a gente se veja como dono depois de aposentar... $\dot{E}$ isto! $\dot{E}$ isto! A cidade precisa ser nossa antes e depois de se aposentar. Acho que isso não é só de Florianópolis, precisa ser em todas as cidades. (Ana, no Mercado Público)

Os trechos da fala de Ana permitem retomar em Lefèbvre (1991) a reflexão sobre o direito à cidade como uma forma de resistência à segmentação do espaço urbano em suas diferentes dimensões (sociais, econômicas, culturais, simbólicas,...). A relação das pessoas com a cidade voltando-se ao interesse material amplia o valor de troca, afastando-se do direito à vida urbana enquanto obra e atividade criadora. Nas falas dos pesquisados, foi marcante a ambiguidade e certa angústia quanto à descontinuidade de encontros entre pessoas e à manutenção do direito a viver na cidade.

\section{O centro de Florianópolis para produzir e consu- mir e, também, para sentir-se vivo}

Neste núcleo, os interlocutores descreveram o centro como um espaço onde podem vender algumas de suas produções caseiras para aumentar a renda e consumir o necessário para sua vida. Entretanto, o motivo de estarem ali não é somente o "valor de troca", favorecido pelo centro de Florianópolis, mas também, a necessidade de se sentirem vivos nas relações, ou seja, encontram o "valor de uso" da cidade em sua "alegria e movimento":

Tenho 73 anos de idade e muita história pra contar [risos]. Me aposentei com 64, trabalhava com serviços gerais. Eu venho pro centro porque não gosto de ficar em casa. Sou uma velha que gosta de alegria e movimento e de escola de samba também ... Como a aposentadoria é pequena, aproveito para vender umas coisinhas de crochê por aqui, têm duas lojas que compram e revendem. Assim, eu venho duas vezes na semana aqui no mercado público, que é meu lugar preferido. (Maria, no Mercado Público)

Dentre os pesquisados, três referenciaram os espaços centrais para produção e consumo e, ao mesmo tempo, um local que lhes confere o sentimento de estarem vivos. Maria, de acordo com citação anterior, contou buscar o centro e o Mercado Público para sentir-se ativa e vender seu artesanato. Moacir, aposentado que trabalha como engraxate nas proximidades da Praça XV, menciona necessitar do trabalho para a garantia do sustento da família e, 
simultaneamente, afirma que "aqui é meu segundo lar, porque, além de trabalhar, eu tenho amigos e me sinto bem". José, na Alfândega, vem ao centro para tratar de atividades de cartório para os filhos e para realizar compras diversas, mas encontra mais do que seu propósito: "Eu sempre trabalhei em um banco aqui no centro. Agora, continuo a andar por aqui quase todos os dias e faço isso com prazer, porque sempre tive muito amor por Florianópolis... assim, acho que estou ajudando a fazê-la crescer".

Por meio destas falas, percebe-se a busca pela construção e participação na cidade, seja pela continuidade do trabalho nos espaços urbanos (produção e consumo), seja pelos significados atribuídos pelos interlocutores aos espaços urbanos e pelas menções ao sentir-se bem, ao amor, à alegria, à ajuda no seu crescimento. Contraditoriamente, identificou-se a preocupação com o consumo da própria cidade, embasada no afastamento dos interesses coletivos em detrimento dos individuais.

Fico chateado, às vezes, porque hoje em dia as pessoas não têm mais tempo de conviver na cidade. Pouco antes de me aposentar já estava ficando assim. Acho que não consegui passar para meus dois filhos a importância de fazer história no local onde moramos, porque eles simplesmente passam por aqui. Estes dias, perguntei pra um deles o que achou das melhorias de um prédio antigo da Felipe Schmidt, que demorou 2 anos para restaurar... e ele me disse que não tinha percebido, sendo que passa na frente todos os dias. Hoje em dia as pessoas estão com a cabeça cheia por querer mais e mais e as coisas que chamam atenção têm a ver com o dinheiro mesmo... é uma pena. (Jorge, na Praça XV)

Ao mesmo tempo que se percebe nos aposentados a busca por inserção e participação na cidade, há certa nostalgia e medo da perda das referências dos espaços urbanos para as próximas gerações. Da mesma forma, foi comum a percepção do próprio consumo dos espaços urbanos por outros interesses que não são, necessariamente, de vida coletiva no uso da cidade. Assim, a cidade é transformada em mercadoria, em um produto com valor de troca, perdendo os traços de totalidade orgânica (Lefèbvre, 1991), que conferiam aos seus habitantes o sentido de pertencimento.

\section{O centro de Florianópolis como espaço para a vivência histórico-familiar}

A vida cotidiana na sociedade capitalista, segundo Lefèbvre (1977), acontece na relação dialética entre três elementos: o trabalho, o lazer e a família. $\mathrm{Na}$ aposentadoria, esta relação modifica-se e apresenta-se em sua negatividade aos sujeitos. O trabalho passa a ser uma referência parcial ou, na maioria das vezes, deixa de ser uma referência, estreitando-se, assim, a função social destes sujeitos com a cidade e, muitas vezes, fazendo com que se substitua as vivências no espaço urbano pelos locais privados (a ideia de aposentadoria como recolhimento aos aposentos). O lazer, entendido como tempo livre para se descansar do trabalho, passa a ser um elemento acessório aos aposentados, visto que não teriam "motivos" para descansar, devido à ausência do trabalho ou, ainda, por não saberem como lidar com o tempo livre disponível para si. Na família, por sua vez, as pessoas seguem suas rotinas e, muitas vezes, não percebem as mudanças vivenciadas pelos que se aposentam.

Os interlocutores desta pesquisa apresentaram importantes referências às vivências históricofamiliares na cidade em termos das lembranças do passado (vivido) e, ao mesmo tempo, as relacionaram com elementos presentes de sua aposentadoria, em uma nova relação dialética entre trabalho, lazer e família. A fala de José, a seguir, retrata alguns aspectos desta compreensão.

\begin{abstract}
Vivi numa época em que Florianópolis era bem diferente, as pessoas se conheciam e se cumprimentavam aqui no centro. Então hoje eu estranho um pouco a vida aqui, depois que me aposentei e minha mulher também, a gente vem pro centro, mas falta alguma coisa. Quando a gente era criança, vinha na missa da catedral a pé, com o pai, a mãe e os meus quatro irmãos, era muito bom. Agora, a gente não consegue nem caminhar direito aqui no centro, porque tem muita gente e, vir de carro, é complicado porque não tem lugar para estacionar. Mas eu gosto daqui, porque tenho muitas lembranças, de toda a minha vida. Meus filhos são advogados e eles não entendem muito bem estas lembranças, porque vivem de outra forma hoje. (José, na Alfândega)
\end{abstract}

A vivência em espaços não reconhecidos e as relações sociais transitórias fazem com que os aposentados experimentem um novo cotidiano, o qual não pode ser entendido, simplesmente, como melhor ou pior do que antes de se aposentar, mas sim com novos símbolos e significados que precisam ser compreendidos pelos sujeitos. A cidade, que se apresentava a partir do trabalho materializado (Carlos, 1994), passa a ser estranhada e percebida de novas formas.

\section{Entre "lugares construídos" e a contínua busca por "lugares"}

As relações dos aposentados pesquisados com o centro de Florianópolis ocorrem entre os "lugares 
construídos", de certo modo, colocados restritivamente para quem se aposenta, e a busca contínua por "construírem seus lugares", pelo habitar. A partir de tal compreensão, apresentam-se algumas considerações acerca das relações identificadas por meio desta pesquisa.

Primeira consideração: as relações dos pesquisados com os espaços centrais da cidade estão atreladas aos seus cotidianos, por isso são relações imersas no real (a cidade atual e o que se faz nela) e no imaginário (a cidade que mudou e as lembranças do passado). Retomando a fala de Maria, o real: "Eu venho pro centro porque não gosto de ficar em casa"; o imaginário: "Sou uma velha que gosta de alegria e de movimento, de escola de samba também". Sendo assim, o cotidiano destes aposentados constrói-se como transitório, identificando-se, ao mesmo tempo, continuidades e descontinuidades em suas vidas. Constrói-se na espacialidade, com sobreposição de imagens e de histórias, de arquitetura e cenas, pois "a cidade cria uma situação, a situação urbana. E o que cria? Nada. Centraliza as criações" (Lefèbvre, 1991, p. 125).

Segunda consideração: os pesquisados narram contradições entre o espaço abstrato e a realidade prática e sensível, entre a cidade como valor de uso e como valor de troca, porém inventam suas alternativas para participar da construção dos espaços urbanos. Lefèbvre (1991) situa os espaços urbanos da cidade como uma "ordem próxima", onde se constroem relações entre as pessoas e pela cultura, e como uma "ordem distante", fundamentada pelas instituições, por códigos e formalidades. Ambas as ordens coexistem na cidade e, por isso, as contradições, essencialmente, estão presentes nos discursos dos interlocutores.

Terceira consideração: aos seus modos, os pesquisados se sentem como parte do urbano, têm medo de perdê-lo e de sua descaracterização. Tentam ocupar estes espaços e fazer com que permaneçam como referência em suas vidas. Afirmam preferir a presença, estar no centro com os amigos do que em casa e, ao mesmo tempo, falam sobre suas lembranças do urbano, das possibilidades de encontros e do futuro da cidade. Estes modos e sentimentos são próprios de quem procura habitar.

Para finalizar, entende-se que as relações dos aposentados pesquisados com os espaços urbanos centrais de Florianópolis constroem-se tanto das imagens do passado, como das possibilidades e contradições do presente e de suas expectativas para o futuro. Mesmo quando não encontram seu "lugar" na cidade, procuram formas de participar e, neste sentido, conforme afirmou Lefèbvre (2008, p. 79): "O ser humano só pode habitar como poeta. Se não the é dado, como oferenda e dom, uma possibilidade de habitar poeticamente ou de inventar uma poesia, ele a fabricará a sua maneira”. Na invenção do cotidiano, tais aposentados buscam criar seus lugares e se inserir como atores nas mudanças em curso dos espaços urbanos que habitam.

\section{Notas}

Refere-se à obra $O$ Direito à cidade, de Henri Lefèbvre (1991).

2 Cidade e espaço urbano são conceitos correlatos, mas não sinônimos. Cidade vincula-se à organização espacial, à forma, a um conjunto de elementos ordenados. Urbano tem origem no Latim urbanus, que significa pertencente à cidade, por isso, entende-se por urbano aquilo que está relacionado com a vida na cidade e com as pessoas que a habitam. Assim, o urbano relaciona-se ao tipo de sociedade, à expressão de ideias, éticas, valores, estética; se realiza como práxis na cidade, através das atividades políticas econômicas e culturais, reunindo todos os elementos da vida social (Lefèbvre, 1991).

3 Novembrada é o nome pelo qual ficou conhecida uma grande manifestação popular contra o Regime Militar implantado em 1964 no Brasil, ocorrida no centro de Florianópolis em 30 de novembro de 1979, quando da visita do então Presidente Figueiredo. A manifestação envolveu cerca de quatro mil pessoas e foi repreendida de forma violenta (Maros \& Baldessar, 2010).

4 No método lefebvriano, há três momentos de investigação, conforme Martins (1996). O primeiro é o descritivo, quando o objeto de estudo é observado e descrito o visível a partir da base teórica. $\mathrm{O}$ segundo momento é o analítico-regressivo, onde se realiza a análise da realidade descrita, considerando contradições e possibilidades. Nesse momento, a realidade é analisada, decomposta e o pesquisador procura datar os acontecimentos, pois as relações capturadas têm idade e data, o vivido é uma combinação prática de coisas, relações e concepções que de fato não são contemporâneas. O terceiro momento é o histórico-genético, conhecido como regressivo-progressivo, no qual se busca a gênese das formações sem perder a ideia de processo. Verificase, nesta fase, que as contradições sociais são históricas e não se reduzem a confrontos de interesses entre diferentes categorias sociais, nem se esgotam em si, porque há possibilidades que ainda não aconteceram.

\section{Referências}

Andrade, C. D. (1992). Poema Rua. Rio de Janeiro: Record.

Antunes, R. (1995). Adeus ao trabalho? Ensaios sobre as metamorfoses e a centralidade do mundo do trabalho. São Paulo: Cortez/Edunicamp.

Antunes, R. (2005). Os sentidos do trabalho: ensaios sobre a afirmação e a negação do trabalho ( $7^{\mathrm{a}}$ ed.). São Paulo: Boitempo.

Canevacci, M. (1993). A Cidade Polifônica. São Paulo: Studio Nobel.

Carlos, A. F. A. (1994). A (re)produção do espaço urbano. São Paulo: Editora USP. 
Carneiro, G. (1987). Florianópolis: roteiro da ilha encantada. Florianópolis: Expressão.

Costa, A. B. (2009). Projetos de futuro na aposentadoria. Dissertação de Mestrado, Programa de Pós-Graduação em Psicologia, Universidade Federal de Santa Catarina, Florianópolis.

British Broadcasting Corporation - BBC Brasil. (2013). Em dez anos, mundo terá mais de 1 bilhão de idosos, diz ONU. Acesso em 01 de outubro, 2013: http://www.bbc.co.uk/ portuguese/noticias/2012/10/121001_populacao_idosa dg.shtml.

Instituto Brasileiro de Geografia e Estatística - IBGE. (2013). Banco de Dados Agregados - Censo 2010. Brasília, DF: Autor. Acesso em 01 de outubro, 2013, em http://www.ibge. gov.br/home/estatistica/populacao/censo2010/

França, L. H. F. P. \& Vaughan, G. (2008). Ganhos e perdas: atitudes dos executivos brasileiros e neozelandeses frente à aposentadoria. Psicologia em Estudo, 13(2), 207-216.

Frigotto, G. (1989). O enfoque da dialética materialista histórica na pesquisa educacional. In I. Fazenda (Org.), Metodologia da Pesquisa Educacional (pp. 69-90). São Paulo: Cortez.

Lefèbvre, H. (1977). Critique de la vie vie quotidienne (Vol.1). Paris: L'Arche Éditeur.

Lefèbvre, H. (1991). O direito à cidade. São Paulo: Moraes.

Lefèbvre, H. (2008). A revolução urbana. Belo Horizonte: Editora UFMG.

Makowiecky, S. (2012). A representação da cidade de Florianópolis na visão dos artistas plásticos. Florianópolis: DIO/ESC. (Diretoria da Imprensa Oficial \& Editora de Santa Catarina)

Maros, A. F. \& Baldessar, M. J. (2010). Olhares sobre a Novembrada: jornalistas contam um episódio da história de Santa Catarina. Intercom - Sociedade Brasileira de Estudos Interdisciplinares da Comunicação. Florianópolis: UFSC. Acesso 11 de novembro, 2013, em http://www.intercom.org. br/papers/regionais/sul2010/expocom/EX20-1326-1.pdf

Martins, J. S. (1996). Henri Lefèbvre e o retorno à dialética. São Paulo: Hucitec.

Minayo, M. C. S. (1993). O desafio do conhecimento. São Paulo: Hucitec.

Minayo, M. C. S. (2007). Pesquisa social: teoria, método e criatividade. Petrópolis, RJ: Vozes.

Soares, D. H. P. \& Costa, A. B. (2011). Aposent-Ação: aposentadoria para ação. São Paulo: Vetor.
Souza, A. (2003, 04 de junho). A Flórida brasileira: o número de aposentados com dinheiro em Florianópolis muda a vida econômica da cidade [on line]. Revista Veja, 1805.

Zanelli, J. C., Silva, N., \& Soares, D. H. P. (2010). Orientação para aposentadoria nas organizações de trabalho: construção de projetos para o pós-carreira. Porto Alegre: Artmed.

\section{Agradecimento}

À Coordenação de Aperfeiçoamento de Pessoal de Nível Superior - CAPES. Processo n 41001010036 e CNPq - Bolsa de Produtividade em Pesquisa, pesquisador 2. Numero do processo PQ 10/2011 307846/2011-3.

Submissão em: 09/12/2013

Revisão em: 28/11/2014

Aceite em: 18/02/2015

Aline Bogoni Costa é doutora em Psicologia pela UFSC.

Professora de Psicologia Organizacional e do Trabalho. Produção científica vinculada aos temas orientação para a aposentadoria, projetos de vida, planejamento de carreira, cotidiano e representações. Endereço para correspondência: Departamento de Psicologia/UFSC. Campus Universitário s/no. Trindade. Florianópolis/SC, Brasil. CEP 88040-970.

E-mail: aline_bogoni@yahoo.com.br

Dulce Helena Penna Soares é doutora em Psicologia Clínica na França e Pós-Doutora pela UFRGS com pesquisa sobre Orientação para a Aposentadoria. Professora aposentada voluntária do Programa de Pós-Graduação em Psicologia da UFSC. Sócia do Instituto do Ser - Orientação Profissional e de Carreira. Tem atuado em consultorias sobre orientação e reorientação profissional, e orientação para aposentadoria. E-mail: dulcepenna@terra.com.br 